\title{
CYBER COMUNIDADES E COMUNICAÇÃO CATÓLICA NA ERA DA INTERNET 2.0: NOTAS E PERSPECTIVAS
}

- KELBER PEREIRA GONÇALVES ${ }^{1}$

1 Doutorando em comunicação pela Universidade François Rabelais - Université de Tours - França. PhD student in communication from the François Rabelais University - Université de Tours - France. E-mail: kelber.pereira@hotmail.com.

Recebido em: 07/01/2019 Aprovado em: 23/08/2019

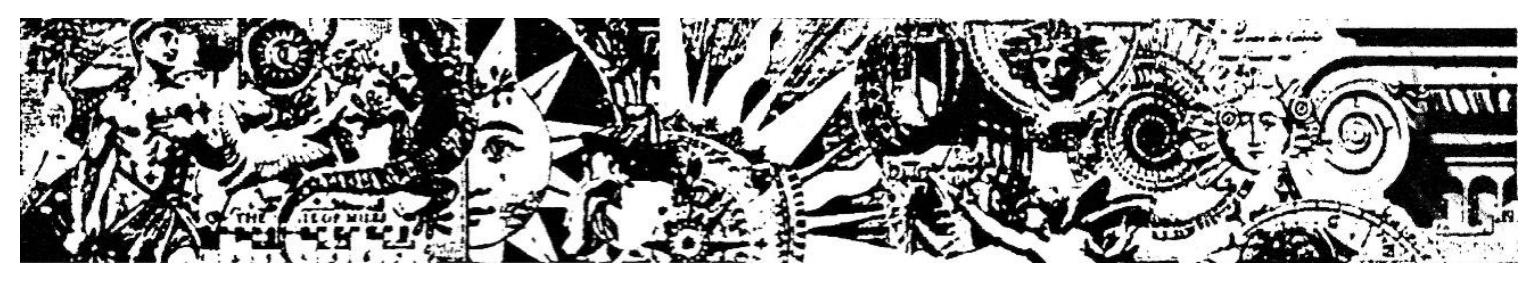

Resumo: Buscamos neste trabalho compreender melhor as perspectivas, no contexto católico nos últimos anos, acerca o uso da internet para o que a Igreja considera como sua missão: "evangelizar do continente digital", concentrando-nos mais precisamente na noção de cyber comunidades religiosas, seu surgimento e suas particularidades. Interessamo-nos sobre as formas como as práticas religiosas ditas "off-line" podem ser reconfiguradas no ambiente digital transformando não somente as dinâmicas geográficas da comunidade, mas também a religião em si. Além de uma reflexão sobre as dinâmicas de (re)negociação, tentaremos identificar possibilidades, desafios e perspectivas futuras acerca deste campo de estudo.

Palavras-chave: Cyber comunidades; religião; internet. 


\title{
CYBER COMMUNITIES AND CATHOLIC COMMUNICATION IN THE AGE OF THE INTERNET 2.0 NOTES AND PROSPECTS
}

\begin{abstract}
We seek in this work to better understand the perspectives in the Catholic context in recent years about the use of the internet for what the church considers as its mission: "to evangelize the digital continent" by focusing more precisely on the notion of cyber-religious communities, their emergence and their particularities. We are interested in the way in which offline religious practices can be reconfigured in the digital environment, transforming not only the geographical dynamics of the community but also the religion itself. In addition to reflecting on the (re)negotiation dynamics, we will try to identify possibilities, challenges and future perspectives about this field of study.
\end{abstract}

Keywords: Cyber communities, religion, internet.

\section{CYBER COMMUNAUTÉS ET COMMUNICATION CATHOLIQUE À L'ĖRE D'INTERNET 2.0: NOTES ET PERSPECTIVES}

Resumé: Nous cherchons dans ce travail à mieux comprendre les perspectives dans le contexte catholique de ces dernières années sur l'utilisation de l'Internet pour ce que l'Église considère comme sa mission: "évangéliser le continent numérique" en nous concentrant plus précisément sur la notion de cyber- communautés religieuses, leur émergence et leurs particularités. Nous nous intéressons à la manière dont les pratiques religieuses hors ligne peuvent être reconfigurées dans l'environnement numérique, transformant non seulement la dynamique géographique de la communauté, mais également la religion elle-même. En plus de réfléchir à la dynamique de (re)négociation, nous essaierons d'identifier les possibilités, les défis et les perspectives futures concernant ce domaine d'étude.

Mots-clés: cyber-communautés, religion, internet.

\section{Introdução}

O aparecimento da "Web 2.0", ou "web participativa", caracterizada por uma maior interatividade e pela simplificação técnica no uso de plataformas e dispositivos digitais, possibilitou uma maior expansão de possibilidades no campo das experiências religiosas on-line. No campo religioso, a internet pode funcionar como um "centro espiritual" permitindo ao internauta compilar e personalizar seu comportamento religioso e crenças (CAMPBELL, 2012) e possibilitar uma desterritorialização de práticas religiosas para além dos espaços religiosos tradicionais (JONVEAUX, 2013), modificando não apenas a noção de comunidade, mas também a própria religião. Inúmeros são os sites destinados a paróquias ou arquidioceses, fóruns ou comunidades religiosas on-line², sites pessoais de líderes religiosos ou laicos que investem no cyber espaço com a ambição de debater questões morais ou teológicas, oferecer conteúdos ou serviços do

\footnotetext{
2 Optamos aqui por utilizar os termos cyber comunidade ou comunidades on-line e não "comunidades virtuais", uma vez que o termo "virtual" é susceptível de transmitir a noção de uma comunidade desvinculada do ambiente "off-line". 
sagrado a partir das cyber comunidades. Entre as inúmeras possibilidades de práticas religiosas midiatizadas através da internet, é possível hoje, no caso dos católicos romanos, rezar o terço ou o rosário, acompanhar uma novena, assistir a uma missa "ao vivo", acender uma "vela virtual", fazer um pedido de oração on-line, midiatizar ou assistir a testemunhos on-line, receber um "aconselhamento espiritual" em tempo real, ler uma "bíblia on-line", escutar "louvores" ou "CDs orantes" através de uma grande variedade de plataformas, fazer uma adoração on-line ao Santíssimo, aprender a elaborar um caderno de oração através de produções audiovisuais no site de compartilhamento YouTube (PEREIRA GONÇALVES, 2017) ou integrar-se a uma comunidade religiosa on-line.

O desenvolvimento de uma demanda do religioso a partir da internet nos últimos anos pode ser traduzida em números. Uma pesquisa realizada no Estados Unidos, no ano 2000, acerca do número de sites católicos no país catalogou 10.000 sites (MAYER, 2008); o número de sites cristãos passou de 610.000 em 1999 a 9,4 milhões em 2004. Em 2008, o termo religion (em inglês) foi usado para 492 milhões de buscas no Google - metade que o termo "sex" e três vezes menos que "money" (DUTEIL-OGATA, 2015). Com uma maior democratização da internet, instituições religiosas emergiram sob a forma de cyber templos, ou cyber comunidades, beneficiando-se dos progressos associados às novas tecnologias da indústria da comunicação e da informação, experimentando novas formas de experiência religiosa, (CAMPBELL, 2010) modificando as próprias estruturas das práticas religiosas tradicionais (CAMPBELL, 2010; 2005). Ainda que, nos primeiros anos de desenvolvimento e de maior democratização da internet, houvesse por parte das comunidades religiosas hesitações quanto ao uso da internet pelo seu "caráter lúdico" ou por um fácil acesso aos "sites de moralidade duvidosa" (MAYER, 2008), de maneira geral, o ajustamento das grandes religiões ao ambiente midiático digital nas última duas décadas parece não ter-se produzido apenas de maneira harmoniosa, mas progressivamente reivindicado.

Buscamos neste trabalho compreender melhor a noção de cyber comunidades religiosas, suas particularidades e de que maneira as práticas religiosas ditas "off-line" são renegociadas e se reconfiguram no ambiente digital transformando não somente as dinâmicas geográficas da comunidade, mas também a própria religião. $O$ texto será dividido em três partes. Num primeiro momento, propomos uma breve perspectiva histórica, retomando alguns dos textos oficiais e posicionamentos no contexto católico nos últimos anos acerca do uso da internet para o que a

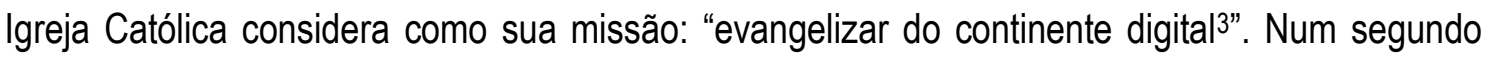

\footnotetext{
${ }^{3}$ Message du pape Benoît XVI pour la 44ème journée mondiale des communications sociales. Disponível em: «https://w2.vatican.va/content/benedictxvi/fr/messages/communications/documents/hf_benxvi_mes_20100124_44thworld-communications-day.html». Acesso em: 12 jul. 2018.
} 
momento, propomos uma reflexão sobre a evolução do conceito da comunidade em sociologia e como estudos se integram no caso das comunidades religiosas on-line. Enfim, num terceiro momento, buscamos identificar como a internet é susceptível de transformar práticas religiosas tradicionais e como essas práticas são (re)negociadas e transformadas para o ambiente digital. Para este estudo, nos apoiamos em um quadro teórico abrangendo os estudos em comunidades on-line (RHEINGOLD, CAMPBELL), mídias e religião (DOUYĖRE, CAMPBELL, HOOVER). Dada a instabilidade do conceito de "comunidade", não se pretende aqui classificar em que medida uma autoproclamada cyber comunidade religiosa seria "de fato" uma "comunidade" em seu sentido sociológico. Propomos uma reflexão sobre dinâmicas de renegociação, buscando identificar desafios e perspectivas futuras acerca desse campo de estudo.

\section{Do uso da internet a uma "ciberteologia da comunicação"}

Ainda que o interesse da Igreja Católica pelos meios de comunicação acompanhe sua gênese ${ }^{4}$, podemos dizer que o reconhecimento mais explícito da importância dos meios de comunicação por parte da Igreja Católica se deu através do Concílio do Vaticano II (1962-1965). No texto Inter Mirifica (que poderia ser traduzido por "entre maravilhas"), a Igreja reconhece que as questões ligadas aos meios de comunicação representam "matéria de tanta importância", e caracteriza tais meios como "maravilhosas invenções da técnica que, principalmente nos nossos dias, o engenho humano extraiu, com a ajuda de Deus" e que deveriam ser usados para "pregar a mensagem de salvação". Foi também durante o concílio que a Igreja teria elaborado a noção de "comunicação social", que representa o "ponto inicial de uma reflexão católica contemporânea sobre os meios de comunicação em uma sociedade onde estes ocupavam um espaço crescente" (DOUYĖRE, 2010). No Concílio do Vaticano II, a Igreja reitera também o direito à recepção de conteúdos midiáticos que sejam "apropriados para a família", bem como o direito a uma informação "verdadeira", e sublinha a responsabilidade moral dos produtores de informação e a necessidade de condições para uma "opinião pública reta", uma vez que a Igreja percebe a opinião pública como uma "poderosa influência em todas as ordens da vida social, pública e privada". Neste sentido, além de demonstrar sua aspiração ao uso dos meios de comunicação para difundir informações e pregar o evangelho, a Igreja considera que é seu dever proteger os homens do "mal", e garantir "a devida perícia nestes meios", os quais devem ser utilizados com objetivos

\footnotetext{
${ }^{4}$ Se pensarmos os meios de comunicação de maneira mais alargada (parole, imagem, texto etc.). No sentido organizacional, uma ordem religiosa alicerçada na comunicação foi instituída ainda na idade média. Ver em Douyère, D. Une organisation fondée pour communiquer : l'Ordre des frères prêcheurs (1215-1228). Paris, L'Harmattan, 2010. 
salvacionistas. Trata-se em Inter Mirifica de uma abordagem que nos parece antagônica àquela por exemplo apresentada na encíclica Vigilante Cura de 1936, endereçada ao episcopado dos Estados Unidos na era de ouro do cinema hollywoodiano, que visava, "qual santa cruzada, reprimir os abusos das representações cinematográficas ${ }^{\prime \prime}$.

O interesse da Igreja Católica pela internet desponta desde os primórdios de seu desenvolvimento. No início dos anos 1990, durante a comemoração do $24^{\circ}$ Dia Mundial das Comunicações Sociais, o papa João Paulo II expõe seu interesse em relação ao avanço no desenvolvimento de computadores: "com o advento das telecomunicações computadorizadas e dos chamados sistemas computadorizados de participação, foram oferecidos à Igreja outros meios para o cumprimento de sua missão"6. Uma década mais tarde, em 22 de novembro de 2001, 0 papa João Paulo II fez uso da internet para enviar por e-mail a partir de Roma a exortação Ecclesia in Oceania para os católicos romanos daquela região do globo (MAYER, 2008). Alguns meses depois, durante a comemoração do $36^{\circ}$ Dia Mundial das Comunicações Sociais, João Paulo II, no texto intitulado "Internet: um novo foro para a proclamação do Evangelho7", convida toda a Igreja "para se fazer ao largo na 'net', de tal maneira que no presente, assim como foi no passado, 0 grande compromisso do evangelho e da cultura possa mostrar ao mundo 'a glória de Deus e o rosto de Cristo"' (2 Cor 4:6).

Outros dois importantes documentos dedicados à internet e publicados em 2002 pela Santa Sé merecem igualmente atenção. Trata-se dos documentos intitulados: "Igreja e Internet 8 " e "Ética na Internet9". No primeiro documento, a Igreja afirma "ter uma finalidade dúplice em relação aos mass media". O termo "internet" aparece 57 vezes no primeiro e 48 vezes no segundo documento. De um lado, a Igreja prioriza o uso "correto" dos meios de comunicação para "o

\footnotetext{
${ }^{5}$ Carta Encíclica Vigilanti Cura do Sumo Pontifice papa Pio XI aos veneráveis irmãos arcebispos, bispos e demais ordinários dos Estados Unidos da América, em paz e comunhão com a sé apostólica sobre o cinema. Disponível em: «http://w2.vatican.va/content/pius-xi/pt/encyclicals/documents/hf_p-xi_enc_29061936_vigilanti-cura.html». Acesso em: 12 jul. 2018.

${ }^{6}$ Mensagem do papa João Paulo II para o 24 Dia Mundial das Comunicações Sociais 1990, "a mensagem cristã na cultura informática atual". Disponivel em: «https://w2.vatican.va/content/john-paulii/pt/messages/communications/documents/hf_jp-ii_mes_24011990_world-communications-day.html». Acesso em: 22 jul. 2018.

${ }^{7}$ Mensagem do papa João Paulo II para a celebração do $36^{\circ}$ Dia Mundial das Comunicações Sociais, "internet: um novo foro para a proclamação do evangelho". Disponivel em: «http://w2.vatican.va/contentjjohn-paulii/pt/messages/communications/documents/hf_jp-ii_mes_20020122_world-communications-day.html». Acesso em: 13 jul. 2018.

8 Pontifício Conselho para as Comunicações Sociais, Igreja e internet. Disponível em: «http://www.vatican.va/roman_curia/pontifical_councils/pccs/documents/rc_pc_pccs_doc_20020228_churchinternet_po.html». Acesso em: 17 jul. 2018.

9 Pontifício Conselho para as Comunicações Sociais, Ética na internet. Disponível em: http://www.vatican.va/roman_curia/pontifical_councils/pccs/documents/rc_pc_pccs_doc_20020228_ethicsinternet_po.html». Acesso: em 13 jul. 2018. 
desenvolvimento, a justiça e a paz da humanidade". Por outro lado, a questão dos meios de comunicação está inserida no que se "refere à comunicação na e pela própria Igreja". Ética na Internet tem como conclusão um conjunto de recomendações para o "bom" uso da internet, nomeadamente pelos líderes religiosos, leigos, educadores e catequistas, pelos pais e pelos jovens. Em Ética na Internet, a Igreja considera que "a internet é o mais recente e, sob muitos pontos de vista, o mais poderoso de uma série de instrumentos de comunicação". No documento, ela aborda também questões relativas a globalização, mercantilização da informação, desigualdades de acesso à informação e questões ligadas à segurança e à privacidade, e também trata de questões relacionadas ao uso de dados. Enfim, a Igreja conclui que a internet pode ser um meio de comunicação que, se bem usado, pode contribuir na promoção da paz e na "compreensão recíproca entre os povos e as nações a nível mundial".

Em 2011 o papa Bento XVI convidou os jovens a fazerem "bom uso das redes sociais" [digitais], incentivando "uma forma de comunicação honesta e aberta, responsável e respeitadora do outro". Em "Verdade, anúncio e autenticidade de vida, na era digital", publicado durante $045^{\circ}$ Dia Mundial das Comunicações Sociais, que trata especialmente da internet, o pontífice declara:

No mundo digital, transmitir informações significa com frequência sempre maior inseri-las numa rede social, onde o conhecimento é partilhado no âmbito de intercâmbios pessoais. A distinção clara entre o produtor e o consumidor da informação aparece relativizada, pretendendo a comunicação ser não só uma troca de dados, mas também e cada vez mais uma partilha [...] Sobretudo os jovens estão a viver esta mudança da comunicação, com todas as ansiedades, as contradições e a criatividade própria de quantos se abrem com entusiasmo e curiosidade às novas experiências da vida. 0 envolvimento cada vez maior no público areópago digital dos chamados social network, leva a estabelecer novas formas de relação interpessoal, influi sobre a percepção de si próprio e por conseguinte, inevitavelmente, coloca a questão não só da justeza do próprio agir, mas também da autenticidade do próprio ser. [...] 0 compromisso por um testemunho do Evangelho na era digital exige que todos estejam particularmente atentos aos aspectos desta mensagem que possam desafiar algumas das lógicas típicas da web ${ }^{10}$ (BENEDICTUS PP. XVI, 2011).

No ano de 2012, o pontífice investe no uso do micro-blog Twitter. Em sua primeira mensagem, ele afirma: "Queridos amigos, eu me uno a vocês com alegria por meio do Twitter. Agradeço por sua resposta generosa. Eu os abençoo a todos de coração". Após a renúncia do papa Bento XVI, o Papa Francisco assume a conta dedicada ao papa, @pontifex. Em 2014, o Papa Francisco, em um comunicado semelhante ao de seu antecessor, convida os fiéis a "serem

10 Mensagem do papa Bento XVI para o $45^{\circ}$ Dia Mundial das Comunicações Sociais,Verdade, anúncio e autenticidade de vida, na era digital. Disponivel em: «http://w2.vatican.va/content/benedictxvi/pt/messages/communications/documents/hf_ben-xvi_mes_20110124_45th-world-communications-day.html». Acesso em: 27 de jul. 2018. 
cidadãos do digital". O papa afirmou ainda considerar a internet como "um dom de Deus" e solicitou aos fiéis, na qualidade de cristãos, engajarem-se pela internet para trazer alento ao "homem ferido", e pediu ainda que a comunicação seja "azeite perfumado pela dor e vinho bom pela alegria11", usando uma fórmula análoga à proferida pelo papa Paulo VI em Inter Mirifica de 1963 acerca dos meios de comunicação. Em 2016, durante as comemorações do $50^{\circ}$ Dia Mundial das Comunicações Sociais, o pontífice criou sua conta oficial no Instragram, @franciscus, e declarou que se iniciava "um novo caminho, no Instagram, para percorrer com vocês a estrada da misericórdia e da ternura de Deus". A mensagem é acompanhada de uma imagem representando o pontifício ajoelhado, de olhos fechados e com as palmas das mãos unidas, de modo a sugerir um momento de oração.

Em 2018, o Papa Francisco grava um vídeo em que afirma:

Aproveitemos as possibilidades de encontro que as redes sociais [digitais] oferecem e que a rede digital não seja um lugar de alienação. Que seja um lugar concreto, um lugar rico de humanidade. Peçamos juntos para que as redes sociais não anulem a própria personalidade, mas que favoreçam a solidariedade e o respeito pelo outro na sua diferença12 (BERGOGLIO, 2018).

Numa perspectiva teológica acerca das transformações do campo religioso realizadas pela internet (SPADARO, 2012), acolhe-se a noção de "ciberteologia" para pensar o ambiente digital baseado na fé católica, partindo de uma abordagem que parece ajustar o axioma católico ao modelo da "internet 2.0" ou internet participativa. A questão da "solidariedade" poderia ser favorecida assim, segundo a fé católica, a partir de um modelo de internet "participativa" baseada numa comunicação horizontal e igualitária sob a forma de comunhão. Um modelo que permitiria mais liberdade criativa e liberdade de acesso à informação. 0 ambiente seria percebido assim não mais como um meio, mas um ambiente no qual as pessoas interagem e modificam sua forma de pensar ou ver o mundo. Neste sentido, "a igreja é chamada a estar onde estão os homens, [e] hoje eles estão também na rede [...] a igreja é, por isso chamada não a usar a rede, mas viver neste ambiente ${ }^{13 "}$ ". Spadaro considera que "conexão não produz necessariamente uma comunhão" e que é preciso evitar que "as novas comunidades considerem a fisicalidade um acessório"

\footnotetext{
${ }^{11}$ Mensagem do Santo Padre Francisco para o XLVIII dia mundial das comunicações sociais "comunicação ao serviço de uma autêntica cultura do encontro". Disponivel em: «https://w2.vatican.va/content/francesco/pt/messages/communications/documents/papafrancesco_20140124_messa ggio-comunicazioni-sociali.html». Acesso em: 13 jul. 2018.

12 Vatican news, Cidade do Vaticano, Papa: as redes sociais são um espaço de encontro e solidariedade. Disponível em: «https://www.vaticannews.va/pt/papa/news/2018-06/intencoes-de-oracao-do-papa-para-junho-de-2018.html». Acesso em: 20 jul. 2018.

${ }^{13}$ Spadaro, A. Entrevista ao Padre Antonio Spadaro, Diretor da Civiltà Cattolica, sobre a Ciberteologia. Agência Ecclesia. Disponivel em: «https://www.youtube.com/watch?v=pMMrDN_ua7s». Acesso em: 17 jul. 2018. 
(SPADARO, 2014, p.66). Neste sentido, ainda que a internet possa ser usada para novos tipos de vivências religiosas, ela não substitui as práticas religiosas ditas "off-line", uma vez que não seria por exemplo possível ter acesso aos sacramentos a partir da internet. No caso da internet, a técnica deve ser "evangelizada" e "colocada a serviço da comunicação" (DOUYÈRE, 2011), ainda que as interações ou as práticas religiosas on-line não substituam uma vivência espiritual "off-line". Assim, ainda que o dispositivo seja mais recente, há uma perspectiva por parte da Igreja Católica que parece seguir uma dinâmica tradicional e histórica do uso conjunto dos meios de comunicação (imagem, parole, texto).

\section{Breve contextualização histórica da noção de "comunidade" em sociologia}

Com o aparecimento da Web 2.0, os internautas puderam se apropriar de um grande leque de novas funcionalidades para comunicar e interagir, nutrir e transmitir um conjunto de dogmas, crenças, ritos, valores e práticas. Com uma maior democratização da internet, assistimos a uma proliferação do que o imaginário coletivo chama vulgarmente de "comunidades virtuais": plataformas onde os indivíduos podem trocar experiências, interagir e alargar suas relações sociais. As novas tecnologias da informação e da comunicação modificaram, pelo menos em parte, as lógicas comunicacionais das religiões nomeadamente no que diz respeito à dimensão territorial, transformada e ultrapassada por essas tecnologias (DOUYĖRE, 2015), o que repercutiu na noção de "comunidade" que tradicionalmente, na concepção cristã, era considerada como "uma comunidade espacial, ordenada e reunida por Deus" (CAMPBELL, 2005, p.35), na qual a paróquia seria o elemento organizador das relações sociais e da vida em comunidade.

Nas comunidades tradicionais em partes do globo onde 0 cristianismo esteve historicamente presente, a igreja, situada frequentemente no centro das vilas ou vilarejos, seguiu sendo durante muito tempo um dos locais de excelência da sociabilização dos sujeitos sociais. Todavia, as transformações sociais ocorridas a partir da Revolução Industrial tais como o êxodo rural e, por conseguinte, o rápido crescimento dos grandes centros urbanos reconfiguraram 0 modo de perceber a comunidade e as relações interpessoais. Neste contexto, o interesse em sociologia pelo conceito de comunidade ganhou maior destaque a partir dos trabalhos realizados pelo sociólogo alemão Ferdinand Tönnies, que elaborou uma distinção entre gesellschaft (sociedade) e Gemeinschaft (comunidade). A primeira estaria associada à vida urbana e designando a sociedade de massas na qual os indivíduos não teriam laços entre eles, mas coabitariam para manter "o funcionamento econômico do conjunto" (SCHMOLL, 2013, p.70), 
enquanto que a segunda, associada à vida rural, designaria um grupo de indivíduos que mantém relações sociais de maneira voluntária e com compartilhamento de sentimentos comuns. Numa ótica mais larga e num contexto de diversidade cultural, o bem compartilhado por seus membros segue sendo, na maioria das vezes, imaterial: uma língua, uma história, uma religião, valores ou normas.

Com o advento da internet, tão logo surgiram os primeiros trabalhos que se interessavam em novas formas de interação coletiva através da rede e que receberam na altura o nome de "comunidades virtuais". Rheingold define as comunidades virtuais como "reagrupamentos socioculturais que florescem na rede quando um número suficiente de indivíduos participam de discussões públicas durante um considerável período de tempo, investindo-se suficientemente de corpo e alma para que a rede de relações humanas possa se tecer no seio do cyber espaço" (RHEINGOLD, 1993, p.6). Entretanto, o autor não desenvolve de maneira mais detalhada as problemáticas relacionadas à medição ou delimitação de tempo e esforço feito pelos indivíduos nas interações possibilitadas pelas cyber comunidades. Rheingold completa sua definição sublinhando que a "comunidade virtual" permite, em um primeiro momento, encontrar novas pessoas e que existiria, num segundo momento, o desejo de prolongar ou não o contato com 0 outro, dentro ou fora do cyber espaço. A partir de uma perspectiva sociocultural, a cyber comunidade pode ser pensada também como designando:

Um conjunto de pessoas constituindo uma rede onde os interesses dos membros se encontram e onde se utiliza um código de comunicação comum através de ligações eletrônicas, interfaces gráficas, símbolos, textos, imagens, esquemas. A comunidade virtual é um nível de consciência, ou seja, de interpretação, consequentemente um nível cultural [...] feita de hábitos, de muita conveniência e de cumplicidade. (HARVEY, 1995, p.33).

Visto que os meios de comunicação, a religião e a cultura estão em constante interação (HOOVER e LUNDBY, 1997), concomitantemente com o desenvolvimento das cyber comunidades "seculares", diversas cyber comunidades religiosas se multiplicaram pela rede. No que diz respeito ao desenvolvimento dos estudos em ciências humanas e sociais das cyber comunidades religiosas, pode-se identificar uma evolução de paradigma que seguiu os próprios avanços tecnológicos. Os estudos das cyber comunidades religiosas podem ser identificadas em quatro fases ou etapas distintas (CAMPBELL, 2016). Os primeiros estudos, nos anos 1990, buscavam descobrir como as práticas religiosas foram importadas para a internet para a criação das "comunidades virtuais" (CAMPBELL, 2016). Tratava-se aí de uma fase mais experimental e descritiva que visava entender melhor em que medida essas comunidades poderiam ser descritas 
ou de que modo se descreviam a si mesmas como "comunidades virtuais". Num segundo momento, houve um maior interesse em identificar características comuns entre essas cyber comunidades religiosas focando os esforços em seu funcionamento. Em seguida, a atenção se voltou a perceber como essas comunidades religiosas inseridas no mundo "off-line" investiam no cyber espaço para melhorar sua visibilidade e promover uma comunicação mais eficaz com seus membros. Nessa etapa, os estudos se concentraram nomeadamente na teorização de práticas on-line e off-line. Nesse momento, houve por parte dos pesquisadores 0 interesse em melhor entender o processo de negociação no uso das novas tecnologias em função de sua história, tradições e valores fundamentais (CAMPBELL, 2010). Numerosas questões e tensões surgiram no seio de grupos mais ou menos entusiastas ou reticentes no uso das tecnologias digitais. Nessa fase, há por parte de inúmeras instituições religiosas a percepção da internet como espaço de evangelização e ferramenta para difundir através da rede discursos e valores das crenças fundamentais. Há por parte dessas organizações o desejo de investir no cyber espaço com fins de conversão e como tentativa de (re)aproximar os laicos. Nesse sentido, houve uma tomada de consciência quanto às possibilidades de difusão em massa proporcionadas pela rede, a qual é percebida como mediadora de solidificação de valores, memórias e crenças a um maior número de pessoas possível. A rede mundial de computadores poderia igualmente ser usada como forma de comunhão entre as diversas filiais das instituições que estavam geograficamente distantes. Houve também o uso das novas tecnologias para o estabelecimento de agendas comunitárias como o horário de missas ou confissões no que concerne à Igreja Católica por exemplo. Nesse contexto, assistimos a um fenômeno de digitalização de rituais ou práticas religiosas que foram se aprimorando à medida que novos dispositivos digitais se aprimoravam. Nos últimos anos, os estudos se concentram na intersecção das práticas religiosas on-line e off-line e se interessam nomeadamente pela adesão e uso das novas tecnologias por parte dos crentes.

A cyber comunidade pode servir ainda como complemento a uma vivência religiosa que se opera off-line. No caso das cyber comunidades religiosas, o seu desenvolvimento e o seu sucesso estão ligados a uma questão que seria chave: a questão da acessibilidade (CAMPBELL, 2005). Assim, no conforto de sua casa, o internauta pode se conectar e encontrar na rede outros internautas com quem pode interagir, num momento por exemplo em que seria inviável participar de uma atividade de sua comunidade no mundo físico. Neste sentido, em qualquer hora do dia ou da noite, o internauta pode se conectar e interagir com outro fiel, evitando a solidão e conseguindo alívio para eventuais angústias ou problemas emocionais. Esta visão da comunidade pode ser 
associada à teoria do third-Place, cunhada por Oldenburg no final dos anos $1980 \mathrm{e}$, portanto, antes da democratização da internet.

A partir de uma reflexão sobre as transformações nos modos de vida e das relações sociais na sociedade americana, o autor propõe um "terceiro lugar", que seria fundamental como um lugar de sociabilização e que completaria o primeiro e o segundo espaço, a casa e o trabalho, respectivamente. Em sua concepção, o terceiro lugar corresponderia a bares, salão de cabelereiro ou todo lugar onde o indivíduo pudesse interagir de maneira voluntária com outros indivíduos, guardando assim suas referências como indivíduo, habitante de um espaço e membro de uma comunidade. Um terceiro lugar "ideal" ou "idealizado" seria assim um espaço onde o indivíduo possa ir sozinho, se ele desejar, a qualquer hora, tendo a certeza de que encontraria os seus semelhantes (OLDENBURG, 1999). Essa acessibilidade, segundo o autor, seria uma das principais características do terceiro lugar, uma vez que essa disponibilidade the permitiria se descontrair e interagir com outras pessoas, combatendo assim a solidão e o tédio. 0 terceiro lugar funcionaria como um lugar para recarregar as energias e aliviar a sobrecarga das expectativas que o indivíduo possui em relação a família ou trabalho, e poderia ser vinculado a uma comunidade on-line. A noção de comunidade seria capaz de "produzir uma sensação boa por causa dos significados que a palavra 'comunidade' carrega - todos eles prometendo prazeres e, no mais das vezes, as espécies de prazer que gostaríamos de experimentar, mas que não alcançamos mais" (BAUMAN, 2003, p.7). Assim, há uma concepção utópica da comunidade que poderia ser interpretada como:

[...] é um lugar "cálido", um lugar confortável e aconchegante. É como um teto sob o qual nos abrigamos da chuva pesada, como uma lareira diante da qual esquentamos as mãos num dia gelado. Lá fora, na rua, toda sorte de perigo está à espreita; temos que estar alertas quando saímos, prestar atenção com quem falamos e a quem nos fala, estar de prontidão a cada minuto. Aqui, na comunidade, podemos relaxar - estamos seguros, não há perigos ocultos em cantos escuros [...] todos nós entendemos bem, podemos confiar no que ouvimos, estamos seguros a maior parte do tempo e raramente ficamos desconcertados ou somos surpreendidos. Nunca somos estranhos entre nós. (BAUMAN, 2003, p. 7)

A comunidade, ainda segundo o autor, poderia ser comparada a "um paraíso perdido no qual gostaríamos de retornar" (RAYMOND apud BAUMAN, 2003, p.9) ou reduzida meramente a um "termo" desprovido de sentido sociológico - e que nunca foi tão usado e banalizado como nas últimas décadas - , razão por que é difícil encontrar, na "vida real", a comunidade de fato (HOBSBAWM apud BAUMAN, 2003, p. 20). O aumento do individualismo produzido por transformações políticas e socioeconômicas "não significa porém o fim da comunidade e das 
interações humanas fundadas num dado local geográfico, mas uma reconstrução de relações sociais, incluindo laços culturais e pessoais fortes que poderiam ser considerados como uma forma de comunidade baseada no indivíduo, seus interesses, seus valores e seus projetos" (CASTELLS, 2013, p. 12-13). As profundas transformações socioculturais, nas últimas décadas, concernentes aos avanços tecnológicos e nomeadamente às novas tecnologias ligadas à internet modificaram a maneira como as pessoas interagem socialmente e a relação que estabelecem umas com as outras. Em sociedades ditas modernas, muitas vezes a informação é privilegiada em detrimento da comunicação (WOLTON, 2009), e, numa perspectiva socioeconômica, "estar informado" pode muitas vezes ser considerado mais importante que "estar junto". Neste sentido, os meios de comunicação participam no processo de construção do que entenderíamos por "realidade", funcionando como verdadeiros meios "de construção de identidades e como espaço de configuração de comunidades" (BARBERO, 1997, p.102). Ademais, os meios de comunicação atuam como agentes fundamentais para a construção de atores sociais ativos e incluídos nos processos democráticos. Enfim, com o aumento das migrações humanas e em especial com a concentração de pessoas nas grandes cidades, a pluralidade cultural apresenta um desafio a mais na busca de valores comuns e no estabelecimento de comunidades. Assim, tendo em vista as dificuldades para garantir a sobrevivência de comunidades na contemporaneidade, seria preciso "fazer enormes esforços para encontrar de alguma maneira o tipo de sociabilidade que nós poderíamos associar à comunidade" (BARBERO, 1997, p.105).

\section{Comunidades religiosas on-line: entre a tradição e as renegociações}

Através das pesquisas realizadas nestas últimas décadas no campo das ciências humanas e sociais que estudam os fenômenos religiosos como as ciências da religião, a antropologia ou a sociologia e particularmente no que toca aos estudos em comunicação e religião e mídias e religião, podemos hoje afirmar que as grandes religiões mundiais entenderam a importância do uso dos meios de comunicação para sua sobrevivência, desenvolvimento e visibilidade no espaço midiático - espaço esse que equivale nas sociedades ditas modernas ao próprio espaço público. Os avanços tecnológicos ligados aos meios de comunicação nomeadamente ao aparecimento da "internet participativa" transformaram igualmente as possibilidades de midiatização do religioso. As religiões "falam" dos meios de comunicação e os meios de comunicação "falam" da religião numa dinâmica em que ambos se utilizam mutualmente (DOUYÈRE e FRÉDÉRIC, 2018). Neste processo, os meios de comunicação "não apenas tratam 
e representam a religião, mas interagem com elas numa dinâmica onde as mídias e a religião se modificam mutualmente" (HOOVER, 2014), num contexto em que as religiões na atualidade se constituem em um conjunto de práticas que, midiatizadas, ganham em visibilidade na esfera midiática e pública. Neste sentido, e numa perspectiva socioeconômica, a religião não escapa das dinâmicas de mercado das indústrias da comunicação e da informação. A religião é hoje, mais que no passado, mais um conjunto de práticas públicas, consumidas de maneira mais personalizada, como bens simbólicos ou mercadorias (HOOVER e CLARK, 2002).

O fenômeno de "customização da fé" ou da individualização do crer (CAMPICHE, 1993, p.129) parece estar associado ao fenômeno de declínio das autoridades religiosas, e ao modelo de internet participativa que parece encontrar nas plataformas on-line um terreno favorável para 0 florescimento de práticas religiosas individuais. Assim como nas outras esferas sociais, o religioso está relacionado às dinâmicas das escolhas pessoais, nas quais sentimentos de autonomia individual são efeitos diretos da modernidade, da educação e das mídias (HOOVER, 2014). Há ainda na contemporaneidade o fenômeno de "crise de representatividade das autoridades religiosas", que se exprime nomeadamente pela "reivindicação de uma pregação livre" (HARRISON apud FATH, 2001, p. 470) e pela "predicação correta das santas escrituras", que corresponderia à "única verdade da mensagem", que é "fonte de legitimação" (WILLAIME, 1986, p. 59). Este declínio da autoridade religiosa representa um verdadeiro desafio para as tradições e instituições religiosas, e acompanha ainda os avanços em termos de tecnologias, nos quais as práticas sociais são incessantemente midiatizadas (HOOVER e LUNDBY, 1997; HOOVER, 2014). Neste sentido, podemos encontrar uma midiatização altamente individualizada ou individualizante de práticas religiosas através da internet. Assim, é possível ouvir pregações ao vivo de religiosos através das redes sociais como Facebook, ou ainda assistir a testemunhos ou pregações a partir do canal YouTube. O processo de individualização seria não apenas cultural, mas produzido pela mundialização e pela vida metropolitana, uma transformação política e econômica e uma comunicação de massa que se tornaram ademais uma mass self communication (CASTELLS, 2009 , p.55). Castells considera ainda que o individualismo não representa o isolamento e o fim das comunidades, já que para ele as relações comunitárias no cyber espaço coabitam harmoniosamente com as relações no espaço local. É também importante assinalar que o individualismo seria então necessário e fundamental na construção do sujeito individual, mas também coletivo. Noutras palavras, o indivíduo irá, através de sua construção individual e identitária, buscar outras pessoas que compartilhem com ele emoções, sentimentos, gostos e valores em comum. Esses processos de negociação se fazem numa análise das práticas religiosas 
tradicionais e na maneira como estas poderiam estar visíveis no ambiente midiático, gerando uma certa admissibilidade. Ainda que em muitas regiões do globo temos assistido a um processo de customização da fé e individualização do crer, as atividades religiosas de modo geral não se fazem de maneira isolada e envolvem ainda e de alguma forma grupos ou comunidades.

Para além, os meios de comunicação midiatizam a religião ao mesmo tempo que a religião produz suas próprias mídias (DOUYÈRE e ANTOINE, 2018). O uso dos meios de comunicação e das novas tecnologias por parte das instituições modificam igualmente a maneira como a religião é pensada e vivida. $O$ investimento das instituições religiosas em uma determinada tecnologia em detrimento de outra não apenas está relacionado com a tradição da instituição, mas também pode alterar a concepção da religião e das próprias práticas religiosas. Nesse processo de midiatização, verifica-se "constante processo de renegociação e tensões entre as próprias lógicas religiosas e as lógicas midiáticas" (MARTINO, 2016, p.56). Há ainda instituições em que tradicionalmente 0 recolhimento e a clausura fizeram parte das práticas religiosas, mas, com 0 advento da internet, tais instituições transformaram-se de maneira profunda. A título de exemplo, uma pesquisa realizada sobre a recepção das novas tecnologias em mosteiros e conventos europeus (JONVEAUX, 2013) relevou que a internet chega ao interior dos muros dessas instituições de duas maneiras. Primeiro, esse processo se daria de forma interna à instituição, advindo do desejo dos monges de não estarem às margens da modernidade; já a forma externa de entrada da internet nesses ambientes ocorre com a chegada de jovens que trazem consigo hábitos de uma vida mundana. Numa perspectiva funcionalista, os computadores nos monastérios são também ferramentas de trabalho, usadas para o gerenciamento das atividades econômicas da instituição, portanto constituem instrumentos úteis para a vida religiosa. A internet facilita a venda de produtos artesanais produzidos pelo mosteiro através de sites de produtos naturais ou orgânicos, que podem, através de hiperlinks, redirecionar o internauta para o site do mosteiro.

Neste sentido, a internet modificou nomeadamente a organização e o funcionamento de instituições religiosas que eram caracterizadas muitas vezes pelo seu "retiro" do "mundo" (JONVEAUX, 2013). Ainda que existam fatores de diferenciação quanto ao uso das novas tecnologias no que diz respeito a gênero, idade, nível de estudos, ou conforme o país ou a natureza das práticas religiosas pelos religiosos, a internet oferece aos mosteiros e conventos possibilidades de visibilidade. Todavia, a escolha do uso de uma nova tecnologia e seus dispositivos correspondentes não se faz somente por questões utilitárias, mas pode também ser feita sob embasamento de séculos de tradição e teologia (CAMPBELL, 2010). No caso dos mosteiros europeus, o uso da internet possibilita, além da presença dos religiosos nas redes 
sociais digitais, a comunicação com o mundo exterior sem que seja necessário deixar a clausura. Ademais, a internet "leva" à casa das pessoas a instituição religiosa que muitas vezes está geograficamente localizada em local remoto ou de difícil acesso e, ao mesmo tempo, proporciona à instituição a possibilidade de "reduzir a diferença de essência entre o monastério e o mundo por meio do virtual, se inserindo na mesma 'rede' de mundos totalmente diferentes" (JONVEAUX, 2013, p. 54). Enfim, no que diz respeito ao uso das redes sociais digitais por parte dos religiosos, as fotografias de perfil que representam, na maioria das vezes, os religiosos durante a profissão solene não escapam, segundo a autora, aos "códigos Facebook", o que atesta um ajustamento harmonioso entre a esfera religiosa e a "modernidade" dos meios digitais infocomunicacionais.

A internet como "centro espiritual" (CAMPBELL, 2012), conjuntamente com as possibilidades oferecidas pelo modelo "Web 2.0" ou "internet participativa", ampliou as possibilidades, permitindo ao internauta usar uma enorme gama de dispositivos digitais para personalizar suas práticas e crenças religiosas, que podem, sob diferentes formas, serem vivenciadas simultaneamente no ciberespaço e nas práticas ditas "off-line". Os meios de comunicação podem ser pensados como ferramentas que fornecem um material bruto para a "construção intencional ou involuntária de significações religiosas entre as pessoas em diversos contextos" (HOOVER e LUNDBY, 1997, p.6). Neste sentido, não se trata mais na contemporaneidade de pensar o uso dos meios de comunicação por parte de instituições religiosas como ferramenta para a transmissão de uma mensagem que seria, numa perspectiva meramente funcionalista, percebida como "eficaz" ou "ineficaz" num contexto de evangelização ou conversão. Para além do uso da internet para a transmissão de mensagens religiosas, e num contexto de crise das instituições religiosas que seria causada em grande parte pelo processo de secularização no caso europeu, a internet parece ser uma das ferramentas mais apropriadas para reaproximar de certo modo aquelas pessoas que estariam "sem comunidades" ou geograficamente distanciadas da religião pela escassez de ministros de culto por exemplo. Ante a descristianização causada em partes pelo envelhecimento do clero, a internet pode ser utilizada no âmbito europeu como uma maneira de encontrar meios de transmitir mensagens religiosas que seriam mais adaptadas à "modernidade religiosa". O projeto retraite dans la ville (retiro na cidade), criado pela Ordem Dominicana na cidade de Lille em 2003, configura um exemplo dessa dinâmica. Trata-se de um site gratuito, aberto a todos e que oferece ao internauta a possibilidade de assistir a vídeos sobre teologia, enviar pedidos de oração, ler textos bíblicos etc. e que tem por objetivo "levar a religião a domicílio" para aqueles que se encontram afastados da religião ou para expatriados francófonos (JONVEAUX, 2007). O retiro espiritual, tradicionalmente associado à quaresma e 
realizado habitualmente em locais ermos, foi neste caso pensado para a vida citadina, e graças à internet há um "deslocamento do religioso" (JONVEAUX, 2007) que permite a recriação de laços com a religião no âmbito de um retiro que pode ser realizado em casa, ou mesmo no trabalho.

\section{Desafios e perspectivas para o estudo das cyber comunidades religiosas}

A religião, como conjunto de valores e conhecimentos, e os meios de comunicação, como mediadores da comunicação nas sociedades contemporâneas ditas modernas, constituem dimensões fundamentais da cultura (HOOVER e LUNDBY, 1997) uma vez que ambos são susceptíveis de criar laços sociais (WILLAIME, 2000). A transformação das culturas religiosas judaico-cristãs consideradas em declínio nas últimas décadas em algumas partes do globo se produziu concomitantemente com o advento da sociedade da informação e da comunicação, na qual os meios de comunicação foram se tornando progressivamente os atores mais importantes da esfera pública (HOOVER e LUNDBY, 1997). Os meios de comunicação e nomeadamente as novas tecnologias não modificam apenas nossa maneira de comunicar, interagir socialmente e perceber o mundo, mas também a própria noção de cultura e de religião. Com os novos avanços em termos de tecnologias, uma "nova cultura da mídia religiosa" ou uma "nova cultura religiosa midiatizada" (HOOVER, 2014) tem emergido nos últimos anos. A internet quando usada para práticas religiosas modifica não só a percepção individual, mas também comunitária do religioso (CAMPBELL, 2005), e interfere diretamente na maneira como as cyber comunidades religiosas se remodelam e se articulam. No que diz respeito ao estudo das comunidades religiosas presentes no ciberespaço e para melhor entender como essas comunidades utilizam as novas tecnologias, é imprescindível que nos interessemos preliminarmente pela "história e tradição de uma determinada comunidade com relação às formas precedentes de mídias e tecnologias" (CAMPBELL, 2010, p.15), uma vez que as práticas ditas "off-line" e on-line estão interconectadas. Neste sentido, um internauta que é assíduo na missa hebdomadária dominical e ativo em uma dada paróquia, por exemplo, pode também assistir à missa a partir de seu computador, trocar informações religiosas com outros internautas a partir de fóruns, manter uma página no Facebook com viés religioso. As experiências religiosas a partir da internet podem ser pensadas assim como experiências complementares àquelas vividas "off-line" (CAMPBELL, 2012).

As comunidades religiosas on-line podem ainda ser entendidas como uma rede de relações que se situa na concepção da internet como "rede das redes" (CAMPBELL, 2010). Neste sentido, "assim como uma rede de computadores é um conjunto de máquinas conectadas por um 
conjunto de cabos, a rede social corresponde a um conjunto de pessoas (ou organizações ou outras redes sociais) ligadas por um conjunto de relações socialmente significativas" (WELLMAN apud CAMPBELL, 2005, p.37). A internet, na qualidade de rede mundial de computadores, oferece a possibilidade de "participação em culturas em comum em nível local, nacional e até mesmo global, de ideias partilhadas, símbolos, questões e valores" (HOOVER, 2014). Neste sentido, a internet, no caso do cristianismo, pode ser uma ferramenta eficaz na "coleta do corpo de cristo digital" nas comunidades religiosas on-line (CAMPBELL, 2005) que estão separadas geograficamente, mas que compartilham um conjunto de crenças, valores e visões do mundo em comum. Muitas dessas comunidades são assim criadas por instituições religiosas num intuito de unificação e com a ambição de estarem mais visíveis e transmitirem de maneira mais organizada mensagens e valores religiosos.

Um primeiro desafio para os estudos das cyber comunidades religiosas está sem dúvidas calcado hoje na rapidez dos avanços técnicos das tecnologias da comunicação e da informação (HELLAND, 2005). Contudo, para além da questão tecnológica, há ainda três dimensões (HOOVER, 2014) que devem ser levadas em conta pelos profissionais que estudam mídia e religião: 1) a dificuldade para interpretar as religiões de maneira mais sofisticada, tendo em vista que se trata de um termo instável e flutuante, nomeadamente num contexto de crescente individualização do crer; 2) a necessidade de entender como a religião participa de outras dinâmicas sociais e como ela interage com a política e a cultura; 3 ) a busca por entender de maneira mais profunda a influência mútua exercida pela religião e pelas mídias na contemporaneidade. Aliada a essa problemática, em um contexto moderno de crescente globalização, migrações e transformações do religioso na esfera pública, o termo "comunidade" continua a ser um termo instável e continua a ser constantemente redefinido. No que diz respeito às comunidades on-line, segundo nossas pesquisas, entre os pesquisadores que estudam esse campo, não há por ora consenso quanto a uma definição a ser utilizada para definir tais comunidades. Ainda hoje, no que toca ao imaginário coletivo, encontramos a ideia de "virtual" quando se fala em cyber comunidades: comunidades que estariam absolutamente desconectadas da "vida real". Trata-se de uma abordagem equivocada e que confere a essas comunidades uma noção de relações humanas que se produziriam de maneira fria ou até mesmo "falsa".

Estudos realizados nos últimos anos acerca das cyber comunidades se concentraram sobretudo nas instituições religiosas e suas percepções a respeito do uso da internet e das novas tecnologias como ferramentas de difusão de mensagens religiosas. Por outro lado, poucos trabalhos concentram-se efetivamente nos fiéis e suas percepções, práticas e interações 
concernente às cyber comunidades religiosas não institucionalizadas (CAMPBELL, 2016). Neste sentido, e num contexto de individualização do crer e de crise de instituições religiosas, seria útil para os estudos futuros conceber uma maior atenção às práticas religiosas populares ou sincréticas, ao fenômeno de dupla ou múltipla afiliação ou ainda nomadismo religioso recorrente em algumas partes do globo, dando particular atenção aos internautas laicos na qualidade de atores fundamentais nas mudanças no campo religioso perpetradas em parte pelo uso da internet e das novas tecnologias da indústria da informação e da comunicação.

\section{Referências}

BAUMAN, Zygmunt. Comunidade: a busca por segurança no mundo atual. Plínio Dentzien. Rio de Janeiro: Zahar, 2013.

CAMPBELL, Heidi. Exploring religious community online: We are one in the network. New York: Ed. Peter Lang, 2005.

CAMPBELL, Heidi. Spiritualising the Internet. Uncovering discourses and narratives of religious Internet usage. In: Krüger, Oliver (ed.): Online - Heidelberg Journal of Religions on the Internet: Volume 01.1 Special Issue on Theory and Methodology, 2005.

CAMPBELL, Heidi. When religion meets new media. London, New York: Routledge, 2010.

CAMPBELL, Heidi. Understanding the relationship between religion online and offline in a networked society. Journal of the American Academy of Religion, Volume 80, Issue 1, 1, 64-93, March 2012

CAMPBELL, Heidi; VITULLO, Alessandra. Assessing changes in the study of religious communities in digital religion studies. Church, Communication and Culture, 1:1, 73-89, 2016

CAMPICHE, R. J. Individualisation du croire et recomposition de la religion. In: Archives de sciences sociales des religions, $n^{\circ} 81,117-131,1993$.

CASTELLS, Manuel. La galaxie Internet. Trad. de l'anglais par Paul Chemla Paris, Fayard, 2001.

CASTELLS, Manuel. Communication Power. New York, USA: Oxford University Press, 2009.

CASTELLS, Manuel. The Impact of the Internet on Society: a Global Perspective. Society, the community, people. Ed. BBVA, spain, 2013.

DOUYÈRE, David. La communication sociale: une perspective de l'Église catholique? Jean Devèze et la critique de la notion de «communication sociale». Communiquer, Revue de communication sociale et publique, n. 3-4, 73-86, 2010. 
DOUYĖRE, David. Une organisation fondée pour communiquer : l'Ordre des frères prêcheurs (1215-1228). Loneux, C., Parent, B. (orgs.). Communication des organisations: recherches récentes, Paris, L'Harmattan, tome 1, p. 145-152, 2010.

DOUYÈRE, David. Les mutations communicationnelles du christianisme catholique au XXe siècle. Hermès, La Revue, (1), 225-235, 2015.

DOUYÈRE, David; ANTOINE, Frédéric. (2018). Penser l'entrelacs des religions et des médias. Revue française des sciences de l'information et de la communication, (13) 2018. Disponível em: «https://journals.openedition.org/rfsic/3756\#quotation». Acesso em: 27 de jul. 2018.

DUTEIL-OGATA, Fabienne. et al. Introduction. Le religieux sur Internet: textes et contextes. In: le religieux sur internet. Duteil-ogata, Fabienne; Jonveaux, Isabelle; Kuczynski, Liliane; Nizard, Sophie (orgs). Association française de sciences sociales des religions. Paris: L'Harmattan, 2015.

FATH, Sébastien. Une autre manière d'être chrétien en France. Socio-histoire de l'implantation baptiste (1810-1950) Genève, Labor et Fides, 2001.

PEREIRA GONÇALVES, Kelber. Les youtubeuses et leur cahier de prières: médiatisation des formes émergentes de communication et d'organisation de la pratique religieuse?. Revista Româna de Jurnalism si Comunicare, 12(2/3), 39-52, 2017. Disponivel em: «http://jurnalismcomunicare.eu/rrjc/abstract_ro.php?id=176». Acesso em: 18 de jul. 2018.

HARVEY, Pierre. Cyberespace and Communautique: Approbation, Groupes, Reseaux. SaintNicolas: Presses Université Laval, 1995.

HELLAND, Christopher. Online religion as lived religion. Methodological issues in the study of religious participation on the internet. Online-Heidelberg Journal of Religions on the Internet, 1(1), 2005.

HOOVER, Stewart. Mídia e religião: premissas e implicações para os campos acadêmico e midiático. Comunicação \& Sociedade, 35(2), 41-68, 2014. Disponível em: «https://www.metodista.br/revistas/revistas-ims/index.php/CSO/article/view/4906/4205». Acesso em: 11 de jul. 2018.

HOOVER, Stewart; CLARK, Lynn Schofield. Practicing religion in the age of the media: Explorations in media, religion, and culture. New York: Columbia University Press, 2002.

HOOVER, Stewart; Lundby, Knut. (orgs.). Rethinking media, religion, and culture. Thousand Oaks : Sage publications, 1997.

JONVEAUX, Isabelle. Une retraite de carême sur Internet. Archives de sciences sociales des religions, (139), 157-176, 2007. Disponível em: «https://journals.openedition.org/assr/9533». Acesso em: 21 de jul. 2018.

JONVEAUX, Isabelle. Dieu en ligne. Expériences et pratiques religieuses sur Internet. Paris: Bayard, 2013. 
MARTíN-BARBERO, Jésus. Mass media as a site of resacralization of contemporary cultures. In: Rethinking media, religion, and culture. Thousand Oaks: Sage publications, 1997.

MARTINO, Luís Mauro Sá. Mídia, religião e sociedade: das palavras às redes digitais. São Paulo: Paulus, 2016.

MAYER, Jean-François. Internet et religion. Paris: Infolio, 2008.

OLDENBURG, Ray. The Great Good Place: Cafes, Coffee Shops, Bookstores, Bars, Hair Salons and Other Hangouts at the Heart of a Community. New York: Marlowe \& Company, 1999.

RHEINGOLD, Howard. The virtual community: Finding commection in a computerized world. Boston: Addison-Wesley Longman Publishing, 1993.

RHEINGOLD, Howard. The virtual community: homesteading on the electronic frontier. Cambridge: Mass., MIT Press, 2000.

SCHMOLL, Patrick. Communauté(s), in D. Frau-Meigs \& A. Kiyindou (dir.), Diversité culturelle à l'ère du numérique. Glossaire critique. Paris: La Documentation Française, 2014.

SPADARO, Antonio. Cybertheology: thinking Christianity in the era of the Internet. Translate by Maria Way. New York: Oxford University Press, 2014.

WELLMAN, Barry; GULIA, Milena. Net-surfers don't ride alone: Virtual communities as communities. In: Networks in the global village. Boulder: Westview Press, 1999.

WILLAIME, Jean. Paul. Profession, pasteur: sociologie de la condition du clerc à la fin du XXe siècle (Vol. 11). Labor et Fides, p. 49-72,1986.

WILLAIME, Jean. Paul. Les médias comme analyseur des mutations religieuses contemporaines. In: Pierre Bréchon et al., Médias et religions en miroir, Presses Universitaires de France "Politique d'aujourd'hui", p. 297-329, 2000.

WOLTON, Dominique. Informer n'est pas communiquer. Paris: CNRS Éditions, 2009. 